\title{
MOUTH ALLOMETRY AND FEEDING HABITS OF SOME MEDITERRANEAN FISHES
}

\author{
Paraskevi K. KARACHLE* and Konstantinos I. STERGIOU \\ Laboratory of Ichthyology, Department of Zoology, School of Biology, Aristotle University, Thessaloniki, Greece
}

Karachle P.K., Stergiou K.I. 2011. Mouth allometry and feeding habits of some Mediterranean fishes. Acta Ichthyol. Piscat. 41 (4): 265-275.

Background. Mouth characteristics are considered important yet restraining factors for food acquisition in fishes. Nevertheless, their relations with total length (TL) are not thoroughly examined. In the present study mouth characteristics were estimated for 61 fish species from the northern Aegean Sea and their relations with TL were established, and the relation of mouth area with feeding habits was tested.

Materials and methods. TL, horizontal mouth opening (HMO), and vertical mouth opening (VMO) were measured in 61 species, and mouth area MA was estimated. Relations between mouth characteristics and TL were established using power regression, and the validity of the power model was tested, using Student's $t$-test. In order to explore whether there is a grouping of species based on their feeding habits, the MA-TL regressions of all species were plotted together and the general regression lines per functional trophic group were compared using analysis of variance. Finally, the relative MA was estimated and related to trophic level.

Results. All relations examined were statistically significant $(P<0.05)$, with only one exception (VMO-TL relation in Dentex dentex). The allometric model (for HMO-TL, MA-TL, and VMO-TL) was valid for the majority of species $(52,47$, and 49 species, respectively), with positive allometry prevailing in the HMO-TL and MA-TL relations, and negative allometry in the VMO-TL relations. The analyses employed revealed that MA, for the same TL, increases faster in carnivores than in omnivores, and that in general carnivorous species tend to have larger mouths than omnivorous ones. Finally, there is a strong positive relation between relative MA and trophic level $(P<0.01)$.

Conclusion. There is a strong relation of mouth characteristics to body length and feeding habits. These relations and the way that MA increases in relation to feeding habits could be attributed to structural changes in order for growing fish to meet their increased energetic demands. Establishing such relations is essential for estimating trophic levels of species, which are key parameters for ecosystem-based management models, when data on species' feeding habits are not available.

Keywords: mouth dimensions, mouth area relations, ecomorphology, Aegean Sea

\section{INTRODUCTION}

Feeding habits, diet composition, and food consumption in fishes have been related to various morphological characteristics notably the mouth (e.g., Karpouzi and Stergiou 2003), gut length (Kapoor et al. 1975, Kramer and Bryant 1995, Karachle and Stergiou 2010) and tail (Palomares and Pauly 1989, 1998, Pauly 1994, Karachle 2008). In particular, mouth shape and position, dentition, branchial spines (in terms of structure and number) and distance between gill rakers, and pharyngeal bone structure are strongly connected to species' feeding and diet composition (Al-Hussaini 1947, Verigina 1991, Wootton 1998, Boyle and Horn 2006).

Mouth gape is considered as an important, yet restraining, factor for food selection, capture, handling, and consumption (Keast and Webb 1966, Kapoor et al. 1975,
Wainwright and Richard 1995, Karpouzi and Stergiou 2003, Makrakis et al. 2008, Goatley and Bellwood 2009). As fish grow, they tend to prey upon a greater size range of food items, and the mean size of the prey consumed increases, a fact more evident in second order carnivores and apex predators (Scharf et al. 2000, 2009, Stergiou and Karpouzi 2002, Karpouzi and Stergiou 2003, Arim et al. 2010). Such an increase in prey-size consumed is generally attributed to both morphological (e.g., ontogenetic mouth size increase) and physiological factors (e.g., vision acuity, increasing swimming ability), that allow predators to consume larger prey (Keast and Webb 1966, Kaiser and Hughes 1993, Juanes 1994, Juanes and Conover 1994, Hart 1997, Wootton 1998, Fordham and Trippel 1999). Therefore, and especially in carnivorous fishes, mouth shape and size can be used for the explanation of inter-

\footnotetext{
${ }^{*}$ Correspondence: Dr. Paraskevi K. Karachle, Aristotle University, School of Biology, Department of Zoology, Laboratory of Ichthyology, Box 134, GR-541 24, Thessaloniki, Greece, phone: +30 2310 998356, fax: +30 2310 998279, e-mail: pkarachl@bio.auth.gr.
} 
and intra-specific feeding diversity (Wainwright and Richard 1995, Karpouzi and Stergiou 2003), whereas mouth opening can be used to explain prey-predator relations (e.g., Keast and Webb 1966, Wainwright and Richard 1995, Karpouzi and Stergiou 2003).

This report expands on that of Karpouzi and Stergiou (2003) who studied the relations between mouth characteristics and body size for 18 fishes from the central Aegean Sea. In this study mouth area was estimated for 61 species from the North Aegean Sea, and mouth characteristics (i.e., horizontal and vertical mouth opening, and mouth area) were related to total length. Additionally, relative mouth area was related to species' trophic level. Finally, patterns of mouth area changes according to species' feeding habits were explored. All the above relations are of great importance, since they contribute to the quantification of prey-size related feeding patterns, which in turn define the ecological role of organisms within the food webs (Karpouzi and Stergiou 2003).

\section{MATERIALS AND METHODS}

Samples were collected in the area of N-NW Aegean Sea, Greece, on a seasonal basis, from June 2001 to January 2006, using commercial fishing vessels (i.e., trawlers, purse-seiners, and gill-netters) and preserved in $10 \%$ formalin (for details see Karachle and Stergiou 2008). In the laboratory, total length (TL), horizontal (HMO), and vertical (VMO) mouth opening were measured, and were used for the estimation of mouth area (MA), based on the assumption that MA shape could be that of an ellipse (Erzini et al. 1997):

$$
\mathrm{MA}=\pi\left(\frac{\mathrm{HMO}}{2}\right)\left(\frac{\mathrm{VMO}}{2}\right)
$$

where $\pi \approx 3.14$.

Overall, HMO, VMO, and MA values were estimated for 61 fish species (6796 individuals; Tables 1-2). The number of individuals $(n)$ examined ranged from six (for Lophius piscatorius, Pagrus pagrus, and Pomatomus saltatrix) to 744 (for Engraulis encrasicolus) (Tables 1-2). The sample size for 49 out of the 61 species was more than 20 individuals $($ mean $=111.3$; median $=55)$.

For establishing relations between HMO-TL, VMO-TL, and MA-TL power regression $\left(Y=a X^{b}\right)$ was used, where $a$ is the coefficient of shape, and $b$ is the power fulfilling the dimensional balance (Lleonart et al. 2000). The use of the allometric model (i.e., $Y=a X^{b}$ ) was based on the fact that it is the most suitable for the identification changes in shape, which is the objective of morphometrics (Peters 1983, Lleonart et al. 2000). Consequently, given the mathematical traits of $b$ as mentioned above, $b$ was tested for difference from 2 , in the case of MA (since the measurement unit of MA is $\mathrm{cm}^{2}$ ), and for difference from 1, in the cases of HMO and VMO, using Student's $t$-test (Zar 1999). The MA-TL regressions of all species were plotted together, so that possible groupings of species and/or trends, according to the functional trophic group of species (as defined by Stergiou and Karpouzi 2002), could be identified. The trophic level $(\tau)$ values used for assigning a species into a functional trophic group were taken from Karachle and Stergiou (2006, 2008). Comparisons between the overall regression lines per functional trophic group (i.e., omnivores with preference to animal material (OA); carnivores with preference to decapods and fish (CD); and carnivores with preference to cephalopods and fish (CC); for details see Stergiou and Karpouzi 2002) were compared using analysis of variance (ANOVA; Zar 1999).

The relative MA (RMA) was estimated, as the ratio of MA to squared TL, i.e.,

$$
\mathrm{RMA}=\frac{\mathrm{MA}}{\mathrm{TL}^{2}}
$$

in order to eliminate the effect of length on MA. RMA was plotted against species' $\tau$ (data from Karachle and Stergiou 2006, 2008)

\section{RESULTS}

The HMO-TL, VMO-TL (Table 1) and MA-TL (Table 2) relations were all significant $(P<0.05)$, with the exception of the VMO-TL relation for Dentex dentex $(P>0.05)$. The allometric model was statistically significant (i.e., $b \neq 1$ for HMO and VMO and $b \neq 2$ for MA; Student $t$-test: $P<0.10$ ) for 52 species in the case of HMO-TL relations, 47 species in VMO-TL relations and 49 species in MA-TL relations (Tables 1-4), whereas the linear one was held for 6,6 , and 8 species, in the cases of HMO, VMO, and MA, respectively (Tables 3-4). Positive allometry (i.e., $b>1$ or 2 ) was predominant in the case of HMO-TL and MA-TL relations and negative allometry (i.e., $b<1$ ) in the case of the VMO-TL relations (Table 1).

There was a statistically significant relation $\left(R^{2}=0.32\right.$; $P<0.01$ ) between RMA and $\tau$ (Fig. 1). The general model relating MA with TL, which resulted from combining the data from the 61 species, is given in Figs. 2-3. When the regressions between MA and TL (equations given in Table 2) for all species were plotted together (Fig. 2), there was not a clear pattern on MA changes according to feeding habits. Yet, when the regression lines were grouped per functional trophic group based on a species' feeding habits, it was evident that for the same TL, MA increased faster for carnivores than for omnivores (Fig. 2). Additionally, the overall regression lines of functional trophic groups differed significantly (ANOVA: OA-CC, $F$-ratio $=2051.20, P<0.001 ; \mathrm{OA}-\mathrm{CD}, F$-ratio $=878.62$, $P<0.001$; CC-CD, $F$-ratio $=981.42, P<0.001)$. 


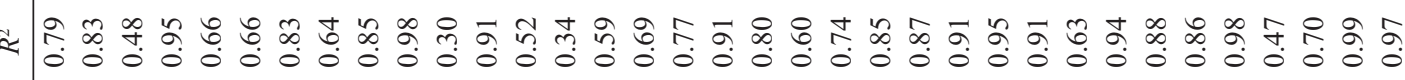

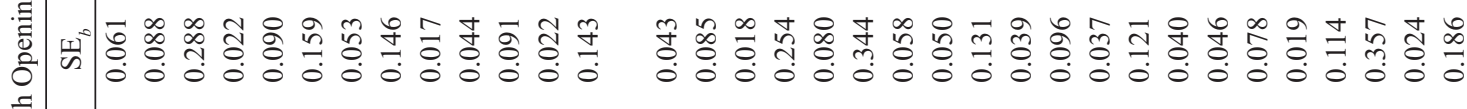

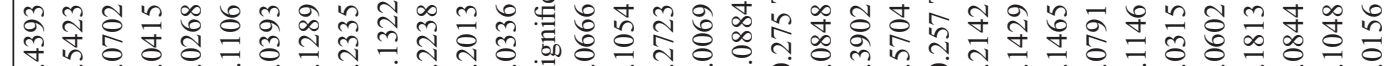
\}

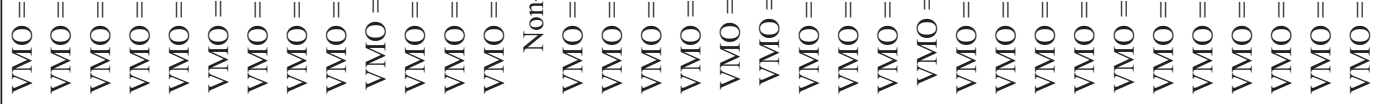

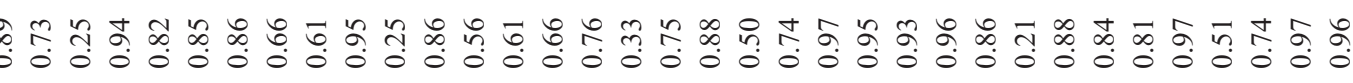

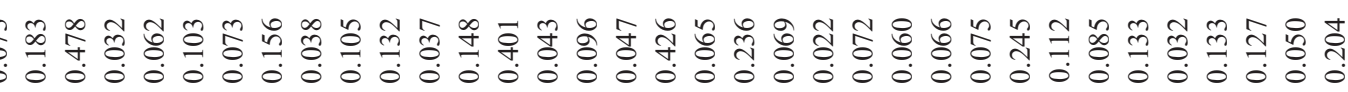

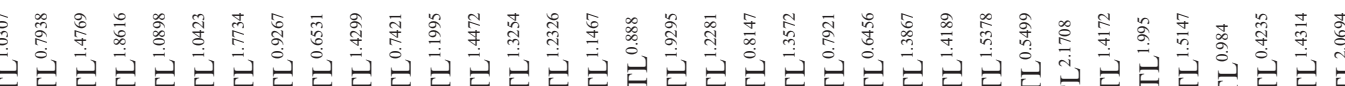

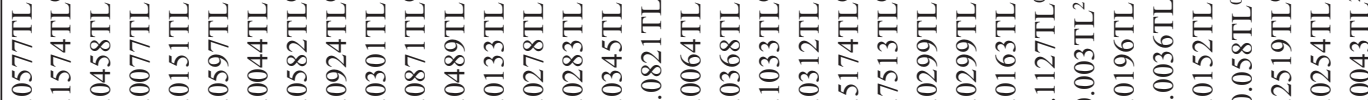

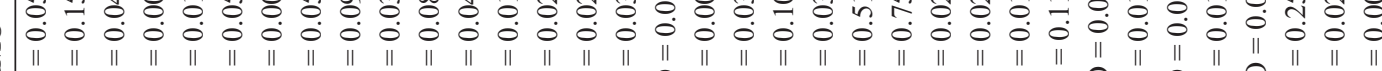

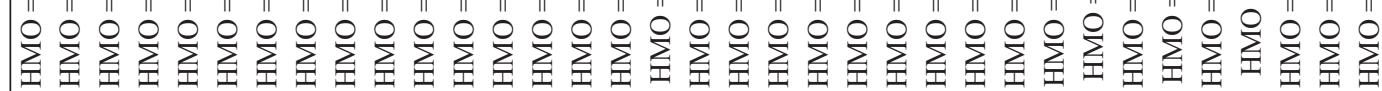

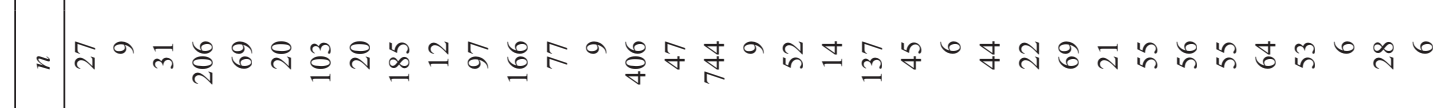

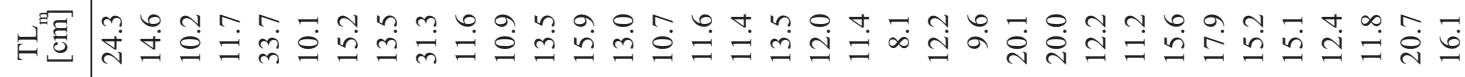
品

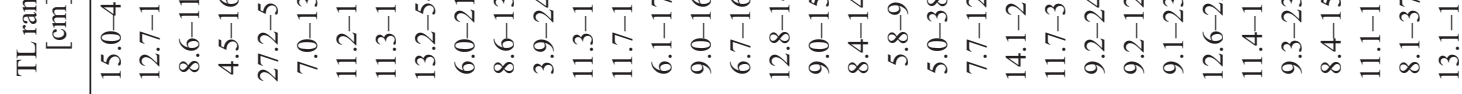
(1)

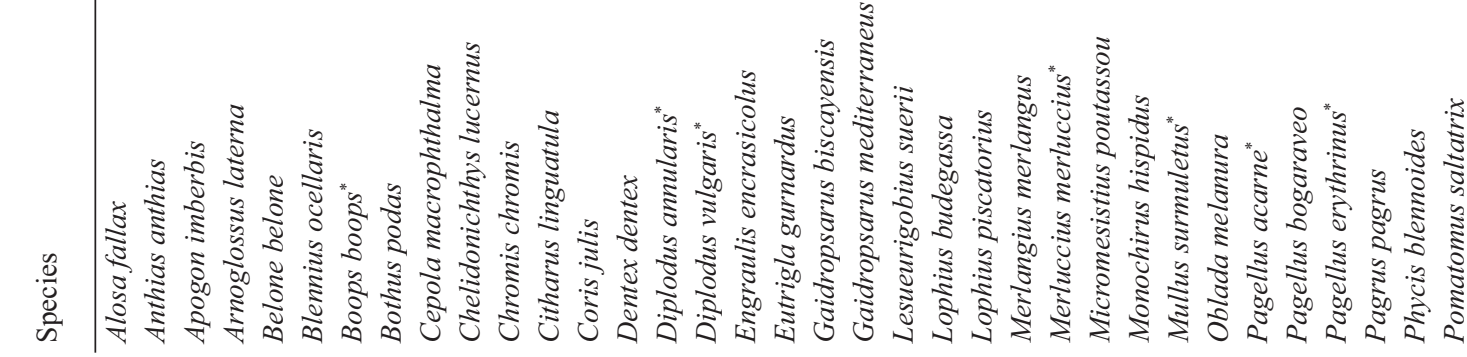


$\frac{\sqrt{0}}{\frac{0}{6}}$

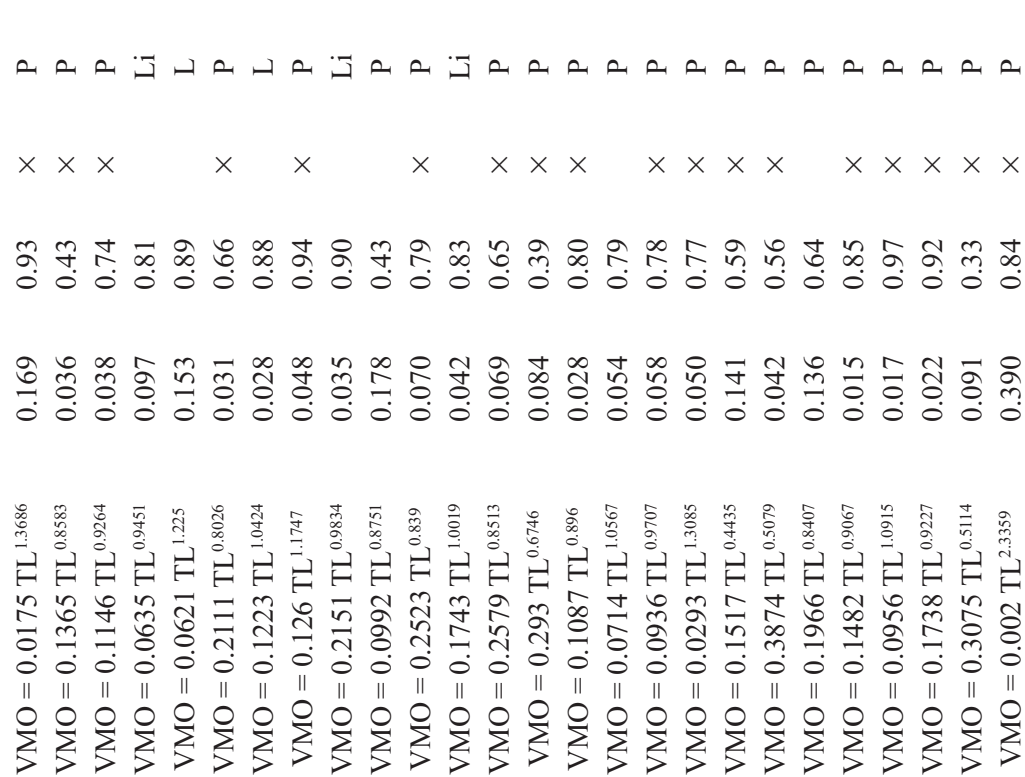

政

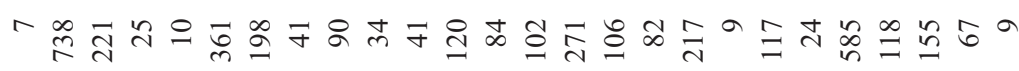

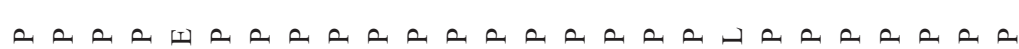

0
80
0
0
0
0
0
0
0
0
0
0
0
0
0
0
0

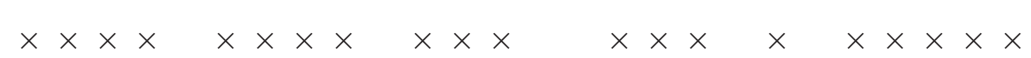

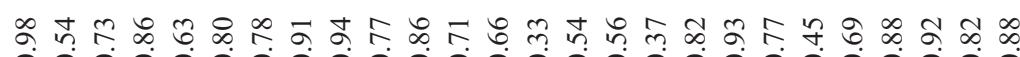

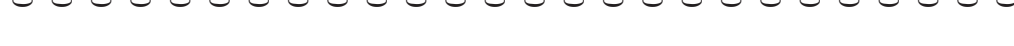

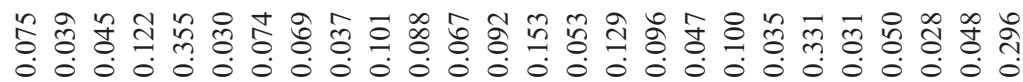

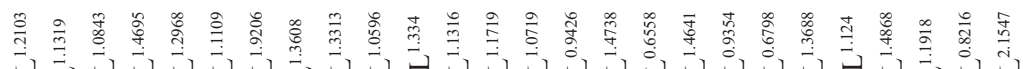

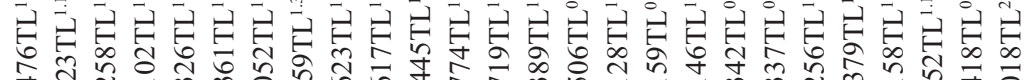

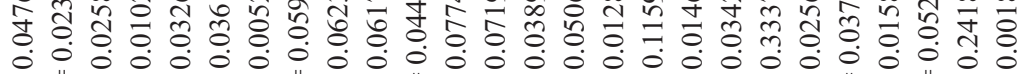
|| || || || || || || || || || || || || || || || || || || || || || || || ||

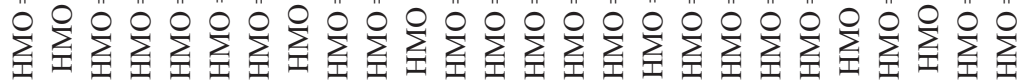

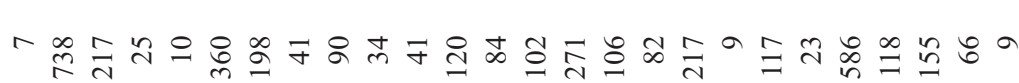

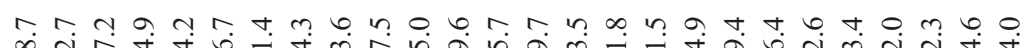

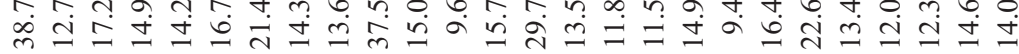

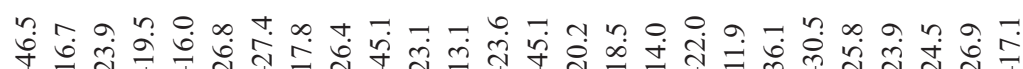

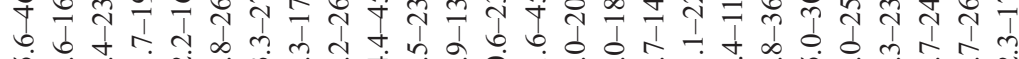

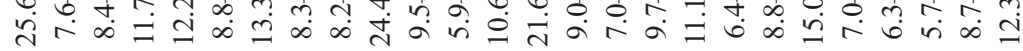

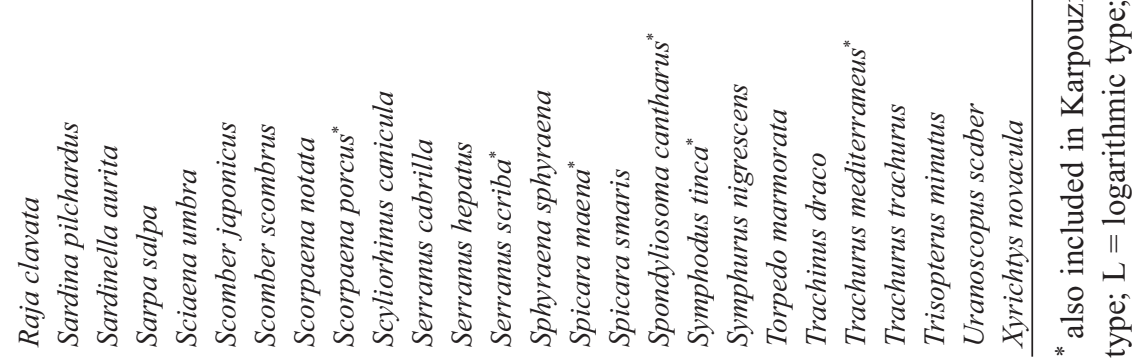


$\frac{\text { No }}{\frac{0}{0}}$

س

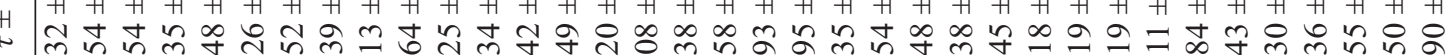

巡

भं

$\simeq$

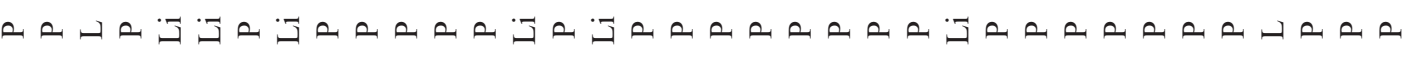

$\times \quad \times \times \times \times$

$\times \times \times \times \times \times \times$

$\times \times \times \times \times$

$\times \times \times$

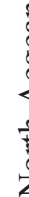

б.

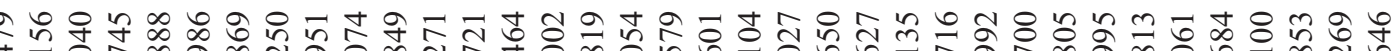

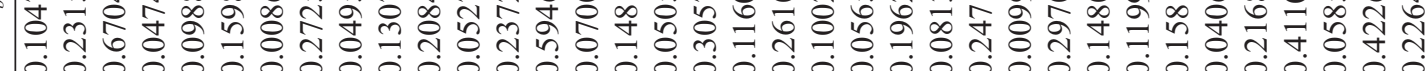
N

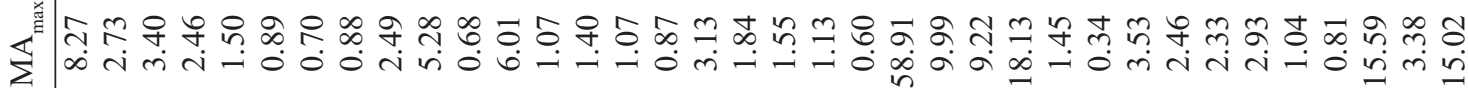

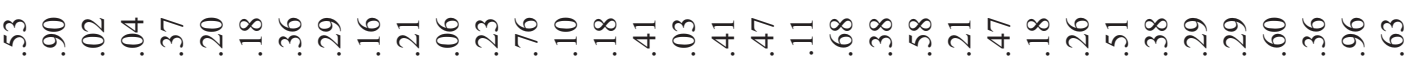

$\sum$

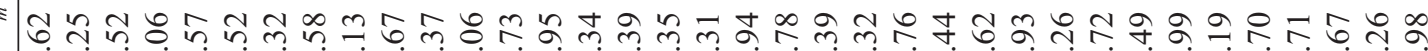

इ

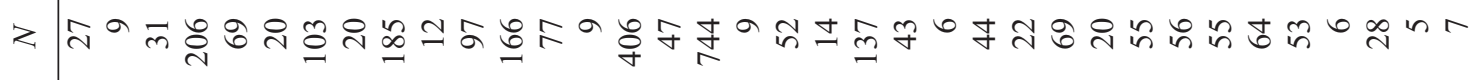

这

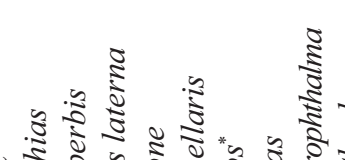

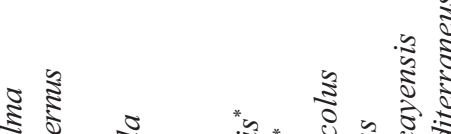

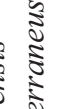


సิำ

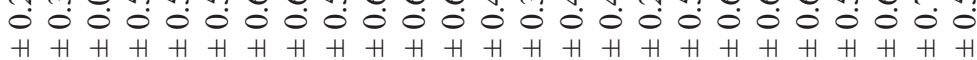

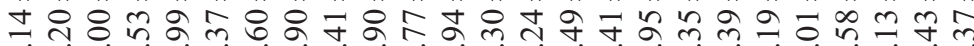

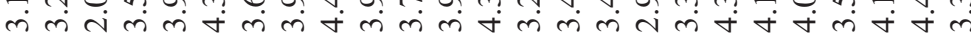

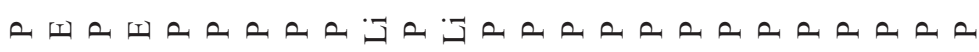
$\times \quad \times \times \times$

$\times \times \times \times \times$ $\times \times \times \times$

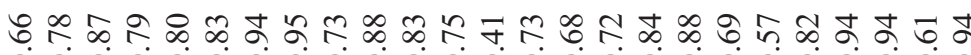
0000000000000000000000000

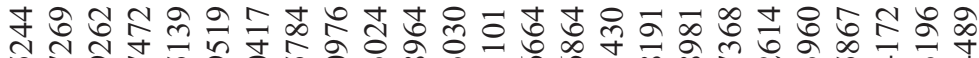

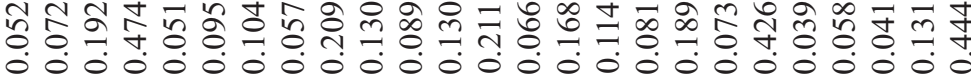

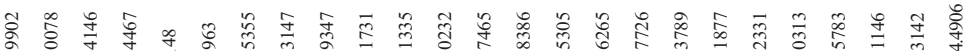

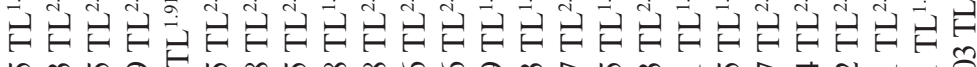
๗ิ)

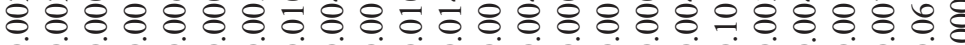
||

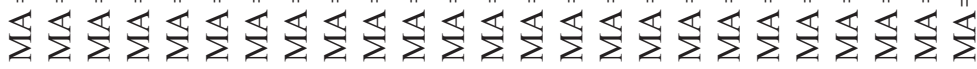

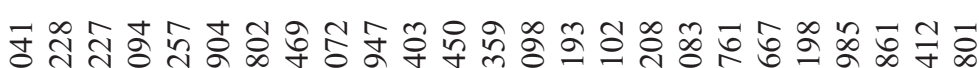
०.0.0.0.0. ба

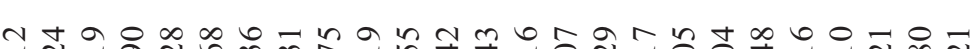

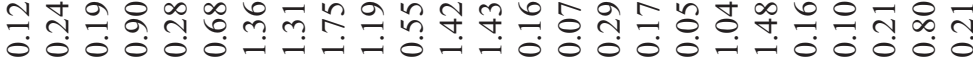

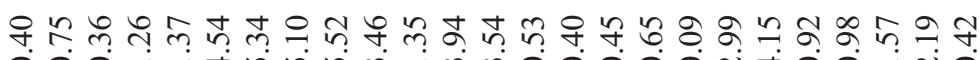

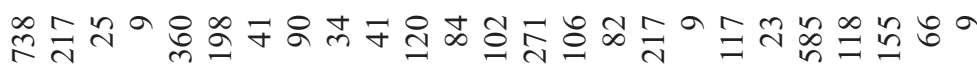

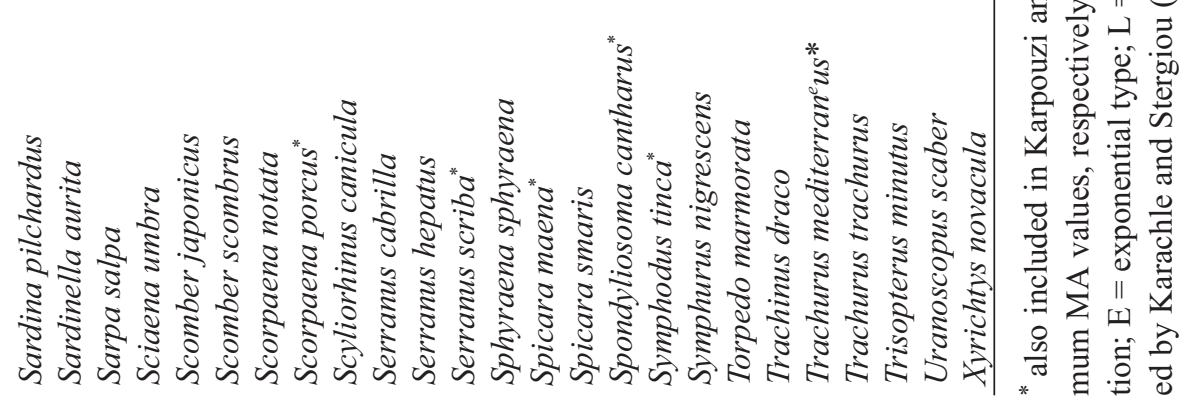




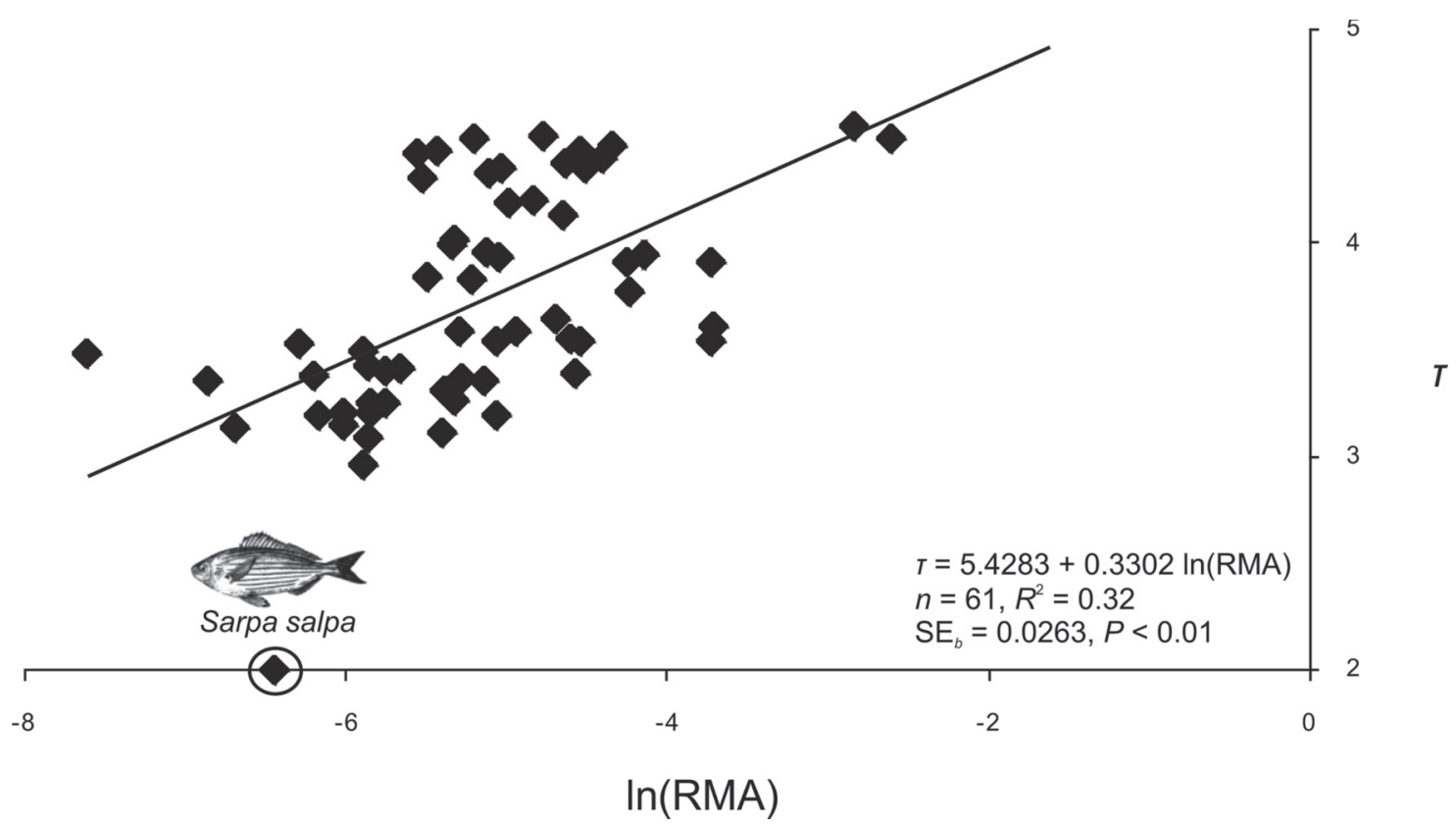

Fig. 1. Regression between relative mouth area (RMA) and trophic level as estimated by Karachle and Stergiou (2006, 2008) $(\tau)$ for 61 fish species from the N-NW Aegean Sea, Greece, June 2001-January 2006; Sarpa salpa deviated from the trend, due to its low $\tau$
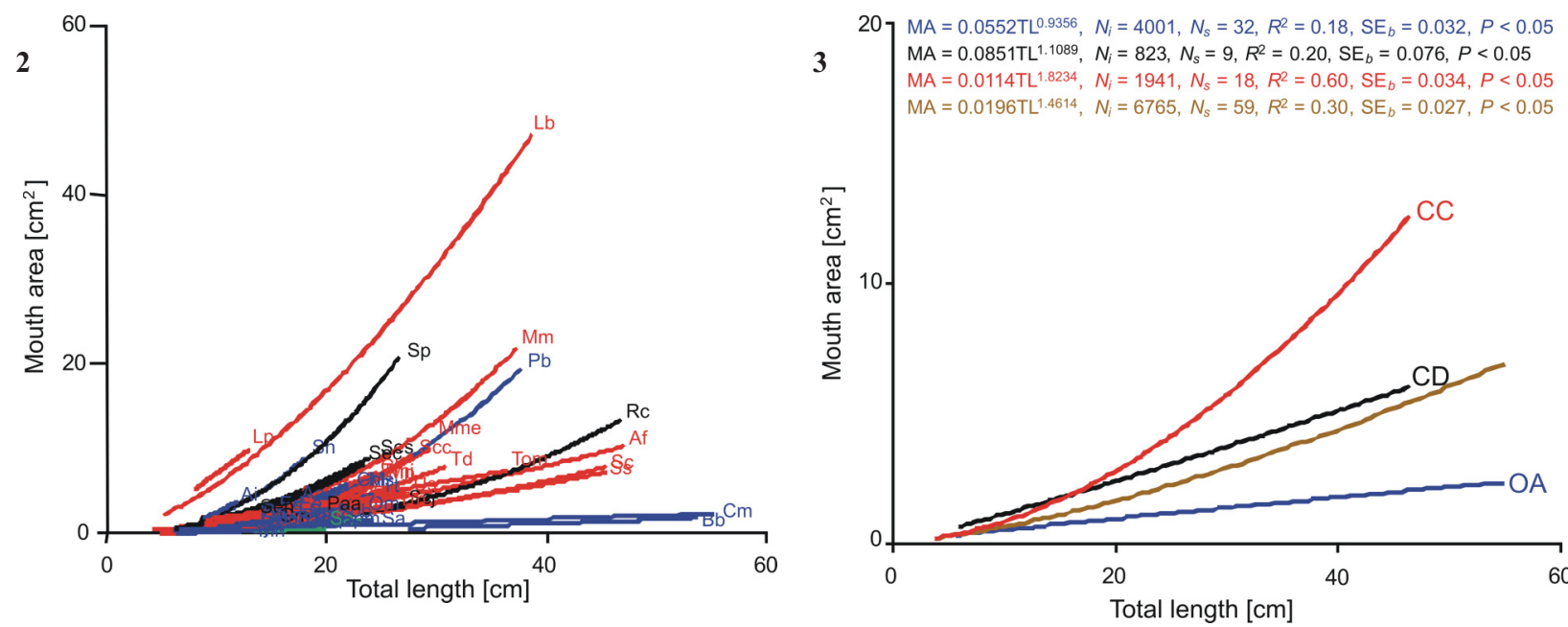

Figs. 2-3. Regressions between total length (TL, in $\mathrm{cm})$ and mouth area $\left(\mathrm{MA}\right.$, in $\left.\mathrm{cm}^{2}\right)$ for 61 fish species from the N-NW Aegean Sea, Greece, June 2001-January 2006 (Equations are given in Table 2); Fig. 2. All regressions of species separately; and Fig 3. regressions of groups of species, according to functional trophic groups (by Stergiou and Karpouzi 2002); Green: herbivores (trophic level $(\tau)=2.0-2.1$ ); blue: omnivores with preference to animal material (OA; $2.9<\tau<3.7)$; black: carnivores with preference to decapods and fish $(\mathrm{CD} ; 3.7<\tau<4.0)$; red: carnivores with preference to fish and cephalopods $(\mathrm{CC} ; 4.0<\tau<4.5)$; and brown: all species combined; $\mathrm{Af}=A$ losa fallax, $\mathrm{Aa}=$ Anthias anthias, $\mathrm{Ai}=$ Apogon imberbis, $\mathrm{Al}=$ Arnoglossus laterna, $\mathrm{Bb}=$ Belone belone, $\mathrm{Bo}=$ Blennius ocellaris, $\mathrm{Bob}=$ Boops boops, $\mathrm{Bp}=$ Bothus podas, $\mathrm{Cm}=$ Cepola macrophthalma, $\mathrm{Chl}=$ Chelidonichthys lucernus, $\mathrm{Cch}=$ Chromis chromis, $\mathrm{Cl}=$ Citharus linguatula, $\mathrm{Cj}=$ Coris julis, $\mathrm{De}=$ Dentex dentex, $\mathrm{Da}=$ Diplodus annularis, Dv = Diplodus vulgaris, Ee = Engraulis encrasicolus, Eg = Eutrigla gurnardus, Gb = Gaidropsarus biscayensis, $\mathrm{Gm}=$ Gaidropsarus mediterraneus, $\mathrm{Ls}=$ Lesueurigobius suerii, Lb = Lophius budegassa, Lp $=$ Lophius piscatorius, $\mathrm{Mme}=$ Merlangius merlangus, $\mathrm{Mm}=$ Merluccius merluccius, $\mathrm{Mp}=$ Micromesistius poutassou, $\mathrm{Mh}=$ Monochirus hispidus, $\mathrm{Ms}=$ Mullus surmuletus, Om = Oblada melanura, Paa = Pagellus acarne, $\mathrm{Pab}=$ Pagellus bogaraveo, $\mathrm{Pae}=$ Pagellus erythrinus, $\mathrm{Pp}=$ Pagrus pagrus, $\mathrm{Pb}=$ Phycis blennoides, $\mathrm{Ps}=$ Pomatomus saltatrix, $\mathrm{Rc}=$ Raja clavata, $\mathrm{Sap}=$ Sardina pilchardus, $\mathrm{Sa}=$ Sardinella aurita, Sas $=$ Sarpa salpa, $\mathrm{Su}=$ Sciaena umbra, $\mathrm{Scj}=$ Scomber japonicus, $\mathrm{Scs}=$ Scomber scombrus, $\mathrm{Sn}=$ Scorpaena notata, $\mathrm{Sp}=$ Scorpaena porcus, $\mathrm{Sc}=$ Scyliorhinus canicula, $\mathrm{Sec}=$ Serranus cabrilla, $\mathrm{Seh}=$ Serranus hepatus, $\mathrm{Ses}=$ Serranus scriba, $\mathrm{Ss}=$ Sphyraena sphyraena, $\mathrm{Spm}=$ Spicara maena, $\mathrm{Sps}=$ Spicara smaris, $\mathrm{Spc}=$ Spondyliosoma cantharus, $\mathrm{St}=$ Symphodus tinca, Syn = Symphurus nigrescens, Tom = Torpedo marmorata, Td $=$ Trachinus draco, $\mathrm{Tm}=$ Trachurus mediterraneus, $\mathrm{Tt}=$ Trachurus trachurus, $\mathrm{Tmi}=$ Trisopterus minutus, $\mathrm{Us}=$ Uranoscopus scaber, $\mathrm{Xn}=$ Xyrichtys novacula . 
$\frac{m}{2}$

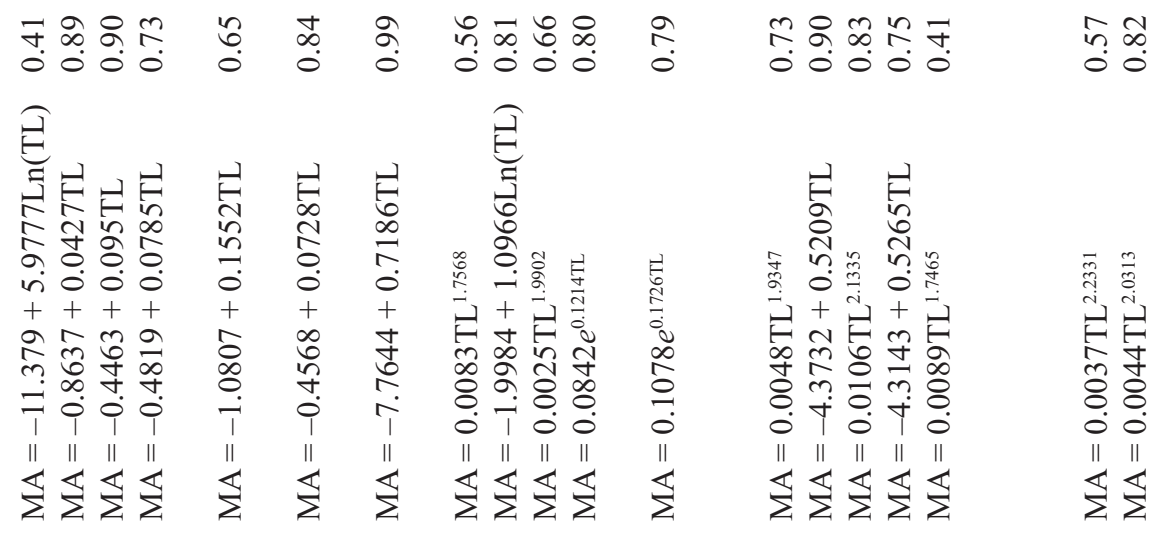

$\sum^{\circ}$

品

응

壳

首

술

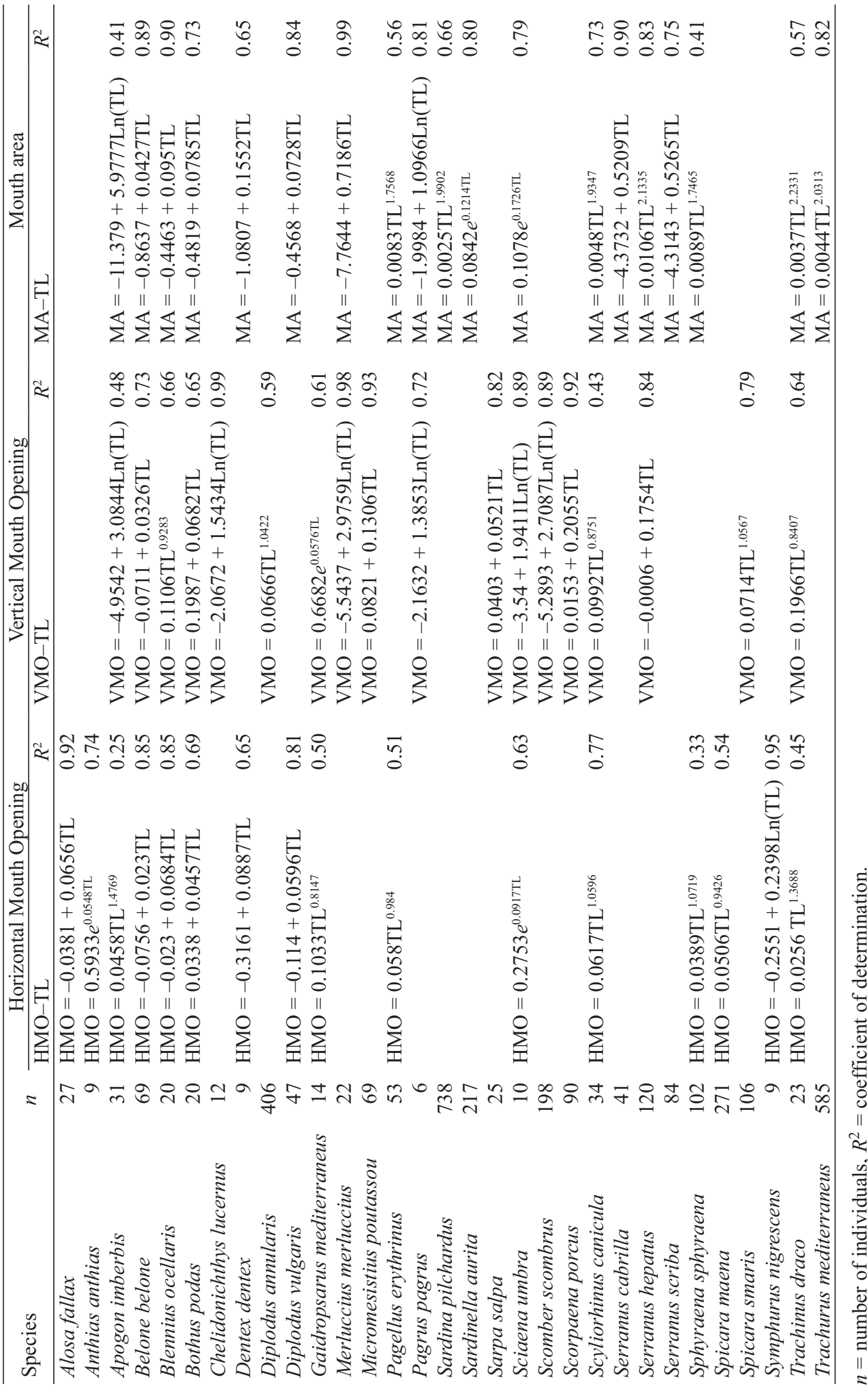


Type of relations between horizontal mouth opening (HMO), vertical mouth opening (VMO), and mouth area (MA) with total length (TL) for 61 fishes from the North Aegean Sea, Greece, June 2001-January 2006

\begin{tabular}{llccc}
\hline \multicolumn{1}{c}{ Type of relation } & & $\mathrm{HMO}^{*}$ & $\mathrm{VMO}^{*}$ & $\mathrm{MA}^{*}$ \\
\hline $\begin{array}{l}\text { Power } \\
(b \neq 1 \text { or 2 statistically significant })\end{array}$ & $Y=a X^{b}$ & $45(73.8)$ & $42(70.0)$ & $42(68.9)$ \\
$(b \neq 1$ or 2 statistically non-significant) & & $7(11.5)$ & $5(8.3)$ & $7(11.5)$ \\
Linear & $Y=a+b X$ & $6(9.8)$ & $6(10.0)$ & $8(13.1)$ \\
Exponential & $Y=a e^{b X}$ & $2(3.3)$ & $1(1.67)$ & $2(3.3)$ \\
Logarithmic & $Y=a+b \ln X$ & $1(1.6)$ & $6(10.0)$ & $2(3.3)$ \\
Positive allometry & $b>1$ or 2 & $45(73.8)$ & $25(41.7)$ & $37(60.7)$ \\
Negative allometry & $b<1$ or 2 & $16(26.2)$ & $35(58.3)$ & $24(39.3)$ \\
\hline
\end{tabular}

* Number of species (percentages are given in parentheses).

\section{DISCUSSION}

In the presently reported study all relations between mouth characteristics (HMO, VMO, and MA) and TL were significant. The allometric model was the dominant model describing the above-mentioned relations, since it accounted for more than $2 / 3$ of the species examined. The same has been reported for other species (Honda 1984, Eggold and Motta 1992, Karpouzi 2001, Lukoschek and McCormick 2001, Karpouzi and Stergiou 2003, Chalkia and Bobori 2006), although other types of models have also been reported (e.g., Erzini et al. 1997, Scharf et al. 2000, Ward-Campbell et al. 2005). The prevalence of the allometric relation could be attributed to the fact that, as fish grow in size the amount of energy required is gradually increasing. In order for the organism to meet the new energetic demands, it is essential to modify its structural capacity (Galis et al. 1994), in order for larger amounts of food and/or bigger size food items to be consumed. An allometric growth of the mouth would ensure that these increased energetic demands will be met, while at the same time the energy required for the acquisition of food will be significantly reduced (i.e., higher amounts of food consumed in fewer feeding attempts). This is consistent with the optimal foraging theory (Gerking 1994). In the majority of cases, MA-TL and HMO-TL relations were positive allometric, while in the case of VMO-TL negative allometry prevailed. The latter can mainly be attributed to the fact that VMO is largely dependent on the bone structure of the skull, whereas HMO is more affected by the muscles and the structure of lips. Additionally, the slower increase of VMO in relation to TL, might be balanced by the way the four-bar-linkage system of the buccal cavity (Gerking 1994, Muller 1996) operates, an hypothesis that need further investigation.

Relations between HMO, VMO, and MA, and TL from the Greek seas are also available for 18 species in the Cyclades (Karpouzi and Stergiou 2003), of which 13 are also included in this study (Tables 1 and 2). In six cases (i.e., Boops boops, Diplodus annularis, Diplodus vulgaris, Mullus surmuletus, Scorpaena porcus, and Symphodus tinca), the type of the relation presented here agreed with those reported by Karpouzi and Stergiou (2003). In the remaining seven cases (i.e., Merluccius merluccius, Pagellus acarne, Pagellus erythrinus, Serranus scriba, Spicara maena, Spondyliosoma cantharus and Trachurus mediterraneus) the type of model was different in the two studies. Such differences could be attributed to the following:

1. Different number of specimens [higher in Karpouzi and Stergiou (2003) for: M. merluccius, P. acarne, P. erythrinus, $S$. maena; and lower for the remaining three] and/or their length range (where it differed noticeably for M. merluccius, P. erythrinus, S. cantharus, T. mediterraneus);

2. Different fishing gears used for sampling [in Karpouzi and Stergiou (2003), specimens were caught using only longlines and gillnets]; and

3. Differences in the quality and/or quantity of available food sources in the different habitats.

Additionally, the validity of the power model was not evaluated statistically by Karpouzi and Stergiou (2003). Nevertheless, usage of such relations should be restricted to the observed length ranges, since many morphologic characteristics are being affected by body size (Piet 1998).

Our results showed that there is a strong positive relation between MA and $\tau$, regardless of TL, indicating that the more carnivorous is a species, the larger is the mouth area, a fact agreeing with the findings of Karpouzi and Stergiou (2003). This also includes small pelagic filter feeders (e.g., anchovies, sardinellas, and sardines) that in general have a relatively low trophic level but relatively large mouth size for their body size. Indeed, when the effect of body size is removed (i.e., estimation of RMA), these species do not deviate from the general trend line. There is only one species that deviated, Sarpa salpa, which has a herbivorous diet (Karachle and Stergiou 2008, Froese and Pauly 2011) and thus a $\tau=2$. This was also clearly revealed when all MA-TL regressions were plotted together. Indeed, MA increased faster with length for carnivorous species than for omnivorous ones, a fact that coincides with the findings of Karpouzi and Stergiou (2003). In general, species with greater mouth gape tend to consume larger prey (Piet 1998). Thus, as proposed by Hugueny and Pouilly (1999) mouth gape could be a good indicator of piscivory in fishes, as well as an indicator of ontogenetic shift in the feeding habits of a given species. 
Establishing general relations between mouth characteristics and trophic levels (and body length) for a large number of species differing in size, shape and habitat will allow us to estimate trophic level of species for which no information on their diet is available. Such estimates are essential for developing of ecosystem-based models for fisheries management, where trophic level values are key parameters.

\section{REFERENCES}

Al-Hussaini A.H. 1947. The feeding habits and the morphology of the alimentary tract of some teleosts living in the neighbourhood of the Marine Biological Station, Ghardaqa, Red Sea. Publications of the Marine Biological Station, Ghardaqa (Red Sea) 5: 1-61.

Arim M., Abades S.R., Laufer G., Loureiro M., Marquet P.A. 2010. Food web structure and body size: trophic position and resource acquisition. Oikos 119 (1): 147-153.

DOI: $10.1111 / \mathrm{j} .1600-0706.2009 .17768 . \mathrm{x}$

Boyle K.S., Horn M.H. 2006. Comparison of feeding guild structure and ecomorphology of intertidal fish assemblages from central California and central Chile. Marine Ecology Progress Series 319: 65-84.

DOI: $10.3354 / \operatorname{meps} 319065$

Chalkia V.V., Bobori D.C. 2006. Length-length and length-mouth dimensions relationships of freshwater fishes of Northern Greece. P. 21. In: 10th International Congress on the Zoogeography and Ecology of Greece and Adjacent Regions, 26-30 June 2006, Patra, Greece.

Eggold B.T., Motta P.J. 1992. Ontogenetic dietary shifts and morphological correlates in striped mullet, Mugil cephalus. Environmental Biology of Fishes 34 (2): 139-158. DOI: $10.1007 / \mathrm{BF} 00002390$

Erzini K., Gonçalves J.M.S., Bentes L., Lino P.G. 1997. Fish mouth dimensions and size selectivity in a Portuguese longline fishery. Journal of Applied Ichthyology 13 (1): 41-44. DOI: 10.1111/j.1439-0426.1997.tb00097.x

Fordham S.E., Trippel E.A. 1999. Feeding behaviour of cod (Gadus morhua) in relation to spawning. Journal of Applied Ichthyology 15 (1): 1-9. DOI: 10.1046/j.1439-0426.1999.00098.x

Froese R., Pauly D. (eds.) 2011. FishBase. [version 02/2011] http://www.fishbase.org.

Galis F., Terlouw A., Osse J.W.M. 1994. The relation between morphology and behaviour during ontogenetic and evolutionary changes. Journal of Fish Biology 45 (Suppl. sA): 13-26.

DOI: 10.1111/j.1095-8649.1994.tb01081.x

Gerking S.D. 1994. Feeding ecology of fish. Academic Press, San Diego, USA.

Goatley C.H.R., Bellwood D.R. 2009 Morphological structure in a reef fish assemblage. Coral Reefs 28 (2): 449-457. DOI: $10.1007 / \mathrm{s} 00338-009-0477-9$

Hart P.J.B. 1997. Foraging tactics. Pp. 104-133. In: Godin J.G.J. (ed.) Behavioural ecology of teleost fishes. Oxford University Press, New York.

Honda H. 1984. Food acquisition patterns in some demersal teleosts. Tohoku Journal of Agricultural Research 35 (1): 33-54.
Hugueny B., Pouilly M. 1999. Morphological correlates of diet in an assemblage of West African freshwater fishes. Journal of Fish Biology 54 (6): 1310-1325.

DOI: $10.1111 / j .1095-8649.1999 . t b 02057 . x$

Juanes F. 1994. What determines prey size selectivity in piscivorous fishes? Pp. 78-100. In: Stouder D.J., Fresh K.L., Feller R.J. (eds.) Theory and application in fish feeding ecology. Belle W. Baruch Library in Marine Sciences. No. 18. University of South Carolina Press, Columbia, SC, USA.

Juanes F., Conover D.O. 1994. Piscivory and prey size selection in young-of-the-year bluefish: predator preference or size-dependent capture success? Marine Ecology Progress Series 114: 59-69.

Kaiser M.J., Hughes R.N. 1993. Factors affecting the behavioural mechanisms of diet selection in fishes. Marine and Freshwater Behaviour and Physiology 23 (1-4): 105-118. DOI: $10.1080 / 10236249309378860$

Kapoor B.G., Smit H., Verighina I.A. 1975. The alimentary canal and digestion in teleosts. Advances in Marine Biology 13: 109-239.

DOI: $10.1016 / \mathrm{S} 0065-2881(08) 60281-3$

Karachle P.K. 2008. Oikologia tīs diatrofīs tōn sīmantikoterōn ichthyapothematōn tou Voreiou Aigaiou. [Feeding ecology of the most important fish stock in the North Aegean Sea.] $\mathrm{PhD}$ Dissertation, Aristotle University of Thessaloniki, Greece. [In Greek.]

Karachle P.K., Stergiou K.I. 2006. Trophic levels of north Aegean Sea fishes and comparisons with those from FishBase. Pp. 22-26. In: Palomares M.L.D., Stergiou K.I., Pauly D. (eds.) Fishes in Databases and Ecosystems. Fisheries Centre Research Reports 14/4.

Karachle P.K., Stergiou K.I. 2008. The effect of season and sex on trophic levels of marine fishes. Journal of Fish Biology 72 (6): 1463-1487. DOI: $10.1111 / \mathrm{j} .1095-8649.2008 .01809 . \mathrm{x}$

Karachle P.K., Stergiou K.I. 2010. Intestine morphometrics: a compilation and analysis of bibliographic data. Acta Ichthyologica et Piscatoria 40 (1): 45-54.

DOI: 10.3750/AIP2010.40.1.06

Karpouzi V.S. 2001. Merikes morfometrikes parametroi pou schetizontai me tī viologia diaforōn eidōn psariōn stī thalassia periochī tōn Kykladōn. [Some morphometrics parameters related to biology of several fish in the marine area off Cyclades Islands, Greece.] BSc Dissertation. Aristotle University of Thessaloniki, Greece. [In Greek.]

Karpouzi V.S., Stergiou K.I. 2003. The relationships between mouth size and shape and body length for 18 species of marine fishes and their trophic implications. Journal of Fish Biology 62 (6): 1353-1365.

DOI: 10.1046/j.1095-8649.2003.00118.x

Keast A., Webb D. 1966. Mouth and body form relative to feeding ecology in the fish fauna of a small lake, Lake Opinicon, Ontario. Journal of Fisheries Research Board of Canada 23 (12): 1845-1874. DOI: $10.1139 / \mathrm{f} 66-175$

Kramer D.L., Bryant M.J. 1995. Intestine length in the fishes of a tropical stream: 2. Relationships to diet-the long and short of a convoluted issue. Environmental Biology of 
Fishes 42 (2): 129-141. DOI: $10.1007 / \mathrm{BF} 00001991$

Lleonart J., Salat J., Torres G.J. 2000. Removing allometric effects of body size in morphological analysis. Journal of Theoretical Biology 205 (1): 85-93.

DOI: $10.1006 /$ jtbi.2000.2043

Lukoschek V., McCormick M.I. 2001. Ontogeny of diet changes in a tropical benthic carnivorous fish, Parupeneus barberinus (Mullidae): relationship between foraging behaviour, habitat use, jaw size, and prey selection. Marine Biology 138 (6): 1099-1113.

DOI: $10.1007 / \mathrm{s} 002270000530$

Makrakis M.C., Nakatani K., Bialetzki A., Gomes L.C., Sanches P.V., Baumgartner G. 2008. Relationship between gape size and feeding selectivity of fish larvae from a Neotropical reservoir. Journal of Fish Biology 72 (7): 1690-1707.

DOI: $10.1111 / \mathrm{j} .1095-8649.2008 .01845 . x$

Muller M. 1996. A novel classification of planar four-bar linkages and its application to the mechanical analysis of animal systems. Philosophical Transactions of the Royal Society of London B 351 (1340): 689-720.

DOI: $10.1098 /$ rstb.1996.0065

Palomares M.L., Pauly D. 1989. A multiple regression model for predicting the food consumption of marine fish populations. Australian Journal of Marine and Freshwater Research 40 (3): 259-273.

DOI: $10.1071 /$ MF9890259

Palomares M.L., Pauly D. 1998. Predicting food consumption of fish populations as functions of mortality, food type, morphometrics, temperature and salinity. Marine and Freshwater Research 49 (5): 447-453.

DOI: $10.1071 /$ MF98015

Pauly D. 1994. Why didn't I think of this? Pp. 74-77. In: Pitcher T.J. (ed.) On the sex of the fish and the gender of scientists. A collection of essays in fisheries science. Fish and Fisheries Series 14, Chapman and Hall, London.

Peters R.H. 1983. The ecological implications of body size. Cambridge University Press, New York, USA.

Piet G.J. 1998. Ecomorphology of a size-structured tropical freshwater fish community. Environmental Biology of
Fishes 51 (1): 67-86.

DOI: $10.1023 / \mathrm{A}: 1007338532482$

Scharf F.S., Buckel J.A., Juanes F. 2009. Contrasting patterns of resource utilization between juvenile estuarine predators: the influence of relative prey size and foraging ability on the ontogeny of piscivory. Canadian Journal of Fisheries and Aquatic Sciences 66 (5): 790-801.

DOI: 10.1139/F09-030

Scharf F.S., Juanes F., Rountree R.A. 2000. Predator size-prey size relationships of marine fish predators: interspecific variation and effects of ontogeny and body size on trophic-niche breadth. Marine Ecology Progress Series 208: 229-248.

DOI: $10.3354 /$ meps 208229

Stergiou K.I., Karpouzi V.S. 2002. Feeding habits and trophic levels of Mediterranean fish. Reviews in Fish Biology and Fisheries 11 (3): 217-254.

DOI: $10.1023 / \mathrm{A}: 1020556722822$

Verigina I.A. 1991. Basic adaptations of the digestive system in bony fishes as a function of diet. Journal of Ichthyology 31 (2): 8-20.

Wainwright P.C., Richard B.A. 1995. Predicting patterns of prey use from morphology of fishes. Environmental Biology of Fishes 44 (1-3): 97-113.

DOI: $10.1007 / \mathrm{BF} 00005909$

Ward-Campbell B.M.S, Beamish F.W.H., Kongchaiya C. 2005. Morphological characteristics in relation to diet in five coexisting Thai fish species. Journal of Fish Biology 67 (5): 1266-1279.

DOI: $10.1111 / \mathrm{j} .1095-8649.2005 .00821 . \mathrm{x}$

Wootton R.J. 1998. Ecology of teleost fishes. 2nd edn. Fish and Fisheries Series No. 24. Kluwer Academic Publishers, London.

Zar J.H. 1999. Biostatistical analysis. 4th edn. Prentice Hall, Upper Saddle River, NJ, USA.

Received: 6 May 2011

Accepted: 1 November 2011

Published electronically: 31 December 2011 